\title{
Family Caregivers' Attitude toward Long-Term Care of Elderly with Psychiatric Disorders and Associated Factors
}

\author{
Farideh Bastani ${ }^{1,}{ }^{*}$ Azar Ramezani, ${ }^{1}$ Hamideh Azimi Lolati, ${ }^{2}$ and Hamid Haghani ${ }^{3}$ \\ ${ }^{1}$ Department of Community Health Nursing and Department of Geriatric Nursing, School of Nursing and Midwifery, Iran University of Medical Sciences, Tehran, Iran \\ ${ }^{2}$ Psychiatry and Behavioral Sciences Research Center, Department of Psychiatry, Addiction Institute, School of Nursing and Midwifery, Mazandaran University of Medical \\ Sciences, Sari, IR Iran \\ ${ }^{3}$ Department of Biostatistics, Iran University of Medical Sciences, Tehran, Iran \\ "Corresponding author: Farideh Bastani, Department of Geriatric Nursing, School of Nursing and Midwifery, Iran University of Medical Sciences, Rashid Yasemi St., Vali-e Asr \\ St., Vanak Sq., Tehran, Iran. Tel: +98-2143651820, Fax: +98-2188201978, E-mail: bastani.f@iums.ac.ir
}

Received 2016 March 29; Revised 2016 July 02; Accepted 2016 September 23.

\begin{abstract}
Background: Providing care for the elderly with psychiatric disorders is a long-term and stressful process leading to some negative outcomes on the caregivers' physical, psychological and social health. In addition, it seems that the caregivers' attitude toward providing long-term cares affects their performance and behavior.

Objectives: The current study aimed to outline the caregivers' attitude toward providing long-term cares for the elderly patients with psychiatric disorders.

Patients and Methods: The current descriptive study was conducted on 200 elderly patients with psychiatric disorders, referred to the Zare teaching psychiatric hospital in Sari, Iran. The participants were selected via convenient sampling method. The sampling lasted from June to mid-November in 2015 .Two questionnaires were applied to collect data, the demographics (the elderly and caregivers) and the short form of Klein attitude toward the provision of long-term care scale (ATPLTC scale). The data were analyzed using descriptive and inferential statistics such as independent T-test, ANOVA and Scheffe test.

Results: The study results indicated that the mean \pm SD age of the caregivers was $51.24 \pm 12.16$ years. Ninety-four percent of the caregivers were married and the education level in $49 \%$ was above high school diploma. Sixty-seven percent of them reported average economic status. The findings showed that $71 \%$ of the caregivers had negative attitude toward long-term care giving. There was a significant relationship between caregivers' education level $(\mathrm{P}=0.017)$, other family members with psychiatric disorder $(\mathrm{P}=0.036)$ and the weekly hours caring for the patient $(\mathrm{P}=0.032)$.

Conclusions: The caregivers' negative attitude toward caring for the elderly patients with psychiatric disorders is an alarm for the mental healthcare policy makers and psychiatric/mental health team workers. To promote the mental health among the elderly patients with psychiatric disorders and those of their caregivers, it is necessary to develop family-oriented education, counseling and supportive programs and perform more studies on the issue.
\end{abstract}

Keywords: Attitude, Caregivers, Elderly, Long-Term Care

\section{Introduction}

In psychiatric disorder, patients undergo several stresses in their personal, familial and social lives. This debilitating chronic malady requires long-time physical, psychological and social care (1). Family caregivers are considered as a part of the informal supportive system, the ones shouldering the main responsibility caring for the patient without receiving any financial reward $(2,3)$. These individuals are known as "the main caregivers". Generally speaking, caregivers of the patients with psychiatric disorders have equivocal, vague and mainly negative attitude toward caring for their patients (4). The formation of caregivers' attitude and perspective to caring for the elderly patients with psychiatric disorders is highly complicated, based on the disease special specifications (5). Attitude is a hypothetical construct not directly ob- servable, rather it accompanies verbal and behavioral statements (6). Attitude in most cases is expressed in two states as positive displaying the individual's interest and inclination to carry out a task. In contrast, negative attitude stands for dislike and/or unwillingness to do that task (7). Birami assumes that the negative attitude of caregivers of patients with psychiatric disorders induces this belief in them that they cannot care for and look after their patient appropriately and feel a sense of failure in this respect (8). In 2007, a study in Australia disclosed that many individuals in the society have negative attitude toward the disease and the patients with psychiatric disorders (9).The results of the research by Caqueo-Urizar showed that family caregivers had negative attitude toward the psychiatric disorders and patients with psychiatric disorders (10). The research by Award et 
al. on family's attitude toward caring for patients with schizophrenia revealed that caregivers' attitude can be influential in improving the living environment, reducing the disease relapse and lowering care pressure among the family members. By accessing sufficient information, knowledge and correct insight, the caregivers can care for and support the patients all-inclusively (11). Khodadady et al. conducted a research titled "Attitude of caregivers of patients with schizophrenia about their method of patient caring at home“, the results of which suggested that the caregivers had positive attitude toward caring for the patients with schizophrenia at home (12). Caring for an old patient with psychiatric disorder is a chronic stressful process resulting in negative outcomes on the caregivers' physical and psychological health (13). Due to providing such patients with long-term care, the caregivers tend to limit their social activity and communication with other kith and kin as much as possible and/or cut it (14). Old age is a natural process in everybody's life that cannot be hindered. Because of reduced physiological capacities, the individuals in this stage of life are prone to come up with chronic maladies and disabilities (15). The health of the elderly has several dimensions, and psychological dimension is the most important one, requiring special attention (16). As a result of deficiencies and lowered selfconfidence, motor deficits, losing relatives and friends, dropped independence and chronic diseases outbreak, an elderly is exposed to a variety of psychotic disorders (17). Of the psychotic illnesses whose outbreak increases by aging, dementia, delirium, amnesia, anxiety and depression disorders can be mentioned (18). The prevalence of psychotic disorders differs in old age. Approximately, $25 \%$ of the ones over 60 have physical disabilities and psychological nuisances (19). The epidemiologic studies conducted in Iran (20) suggest that the prevalence of a wide variety of psychological disorders varies from $9 \%$ to $23.5 \%$. According to the acquired census in Iran, the outbreak of psychiatric disorders in the elderly is reported 23.6\%. The outbreak of psychiatric problems among the elderly females and males is around $26.5 \%$ and $21.5 \%$, respectively nationwide (21). Family caregivers in most cases do not have the essential knowledge and awareness to look after and care for the patients and do not get assistance from the health sector experts and as a result, they are left alone to care for their patients (22). The sort of psychosis, the disease duration and severity, the care duration, the patient's nerve-raking behaviors and reduced social supports can result in negative perception and attitude in the caregivers $(23,24)$. Family caregivers are taken as the main body and the most significant support system in health programs. It seems that the type of caregivers' outlook can play a decisive role and is a very critical factor in caregiving .For this purpose; first, it is required to preliminarily evaluate the caregivers' attitude toward applying the resulted knowledge as the basis for family-orientated cares and promote psychological health level in the elderly and family caregivers. Thus, the current study aimed to determine the family caregivers' attitude toward providing long-term cares for the old people with psychiatric disorders and the related factors.

\section{Objectives}

The current study aimed to analyze the attitude toward providing long-term cares and its associated factors among the caregivers of the patients with psychiatric disorders.

\section{Patients and Methods}

The current descriptive study was conducted on 200 elderly patients with psychiatric disorders, referred to the Zare teaching psychiatric hospital in Sari, Iran. The participants were selected through convenient sampling method. The data collection lasted five months from June to mid-November in 2015. The inclusion criteria were being the main caregiver, the close relatives of the old patient with psychiatric disorder (spouse, sibling, child) that were responsible for the physical and psychological needs and managed the treatment plan of the elderly patient. The elderly care duration should exceed six months .The caregivers should be literate and 20 - 70 years old. The exclusion criteria were the history of taking psychiatric and cognitive, psychological and acute physical disorders' treatment drugs.

\subsection{Ethical Considerations}

The study was approved by the ethical committee of Iran University of Medical Sciences in Tehran, Iran. The caregivers were informed verbally and in writing about the purpose of the study. In this study, the caregivers had the right to decide on participating in the study. The data were confidential.

\subsection{Data Collection Tool}

The data were gathered by two questionnaires:

The one on demographics (the elderly patients and caregivers): the demographics for the old patients (age, gender, marital status, education, type and duration of psychiatric disorder, employment and insurance type) and those of the caregivers (age, gender, marital status, kinship, education, economic status, employment, the number of other patients in the family with psychiatric disorders and weekly care hours). The 26-item questionnaire of 
attitude toward the provision of long-term care (ATPLTC) was first developed by Waldo Klein in 1992 to measure the attitude of the caregivers of the elderly with disability and handicapped children regarding informal long-term care provision; it was psychometrically revised by Linda Mc Laughlin and presented as the modified 14-item questionnaire of the main version exclusively for the elderly with disabilities and chronic diseases cared for by their families. The McLaughlin questionnaire of ATPLTC: it includes 14 five-point Likert scale items as strongly agree $=1$, moderately agree $=2$ and neither agree nor disagree $=3$, moderately disagree $=4$ and strongly disagree $=5$. Higher scores stand for more positive attitude toward long-term care provision. Its Alpha-Cronbach was 0.88 as reported (25). The above tool had not been applied in Iran so far. Therefore, first the questionnaire was translated by three translators (two experts familiar with medical terms and a bilingual translator). Content validity was applied for the questionnaire's scientific validity. The questionnaire was handed to 10 Iran Midwifery Nursing College faculty members and their comments were collected and applied in the questionnaire and its final version was utilized by the experts' discretion. To assess the reliability, 20 questionnaires were distributed among the caregivers. After being completed, the reliability and the internal correlation coefficient were computed, its Alpha Cronbach was 0.76 . SPSS ver. 21 was employed to analyze the data, the descriptive statistics (frequency, mean and standard deviation) and the inferential statistics (ANOVA and independent T-test and Scheffe test) were used.

\section{Results}

The data analysis revealed that $52 \%$ of the caregivers were male, $94 \%$ of whom were married. The age range of caregivers was $20-70$ and their mean age was $51.42 \pm 12.69$ years. The majority of the caregivers (48.5\%) were the children and after that the spouses (29.5\%) of the elderly. Education level in $49 \%$ of the caregivers was above high school diploma; the majority were housewives or self-employed. More than half of them (67.8\%) had average economic status; $86.4 \%$ of the caregivers had only looked after the elderly with psychosis, $86.4 \%$ of them had merely cared for the elderly with psychotic disorders and $13.6 \%$ of the caregivers had looked after another patient with the psychiatric disorder, in addition to caring for an elderly with similar disease at home.

The mean of the weekly care hour in the study was $34.24 \pm 10.09$. The maximum weekly care level ranged 35 - 44 hours (Table 1 ).

According to the study demographic data, $51 \%$ of the subjects were male, $54.5 \%$ married, $5 \%$ single and $40.5 \%$ widow. Their minimum age was 60 and maximum 90 years with the mean age of $71.69 \pm 7.27$ years; $66.5 \%$ of the subjects were under high school diploma and $11.5 \%$ had higher educations. In terms of employment, $46.2 \%$ of the patients were unemployed and had no income, $24.6 \%$ farmers, $2.6 \%$ were self-employed and $26.6 \%$ retired. Also, $42.7 \%$ of the elderly were afflicted with psychiatric disorder for 10 to 20 years and the mean disease duration was $18.05 \pm 9.56$ years. The common psychiatric disorders were depression, schizophrenia and mania with the frequency of $31.5 \%, 29.5 \%$ and $21.5 \%$, respectively (Table 2 ).

The findings in Table 3 revealed that $71 \%$ of the caregivers had negative attitude toward long-term care provision and the mean $\pm S D$ attitude was $39.39 \pm 5.32$. The independent T-test and ANOVA displayed that out of the caregivers' demographics, educational level $(\mathrm{P}=0.017)$, other family members of the patient with psychiatric disorder $(\mathrm{P}$ $=0.036)$ and weekly care hours $(\mathrm{P}=0.032)$ had significant statistical relationship with attitude. Post hoc Scheffe test revealed that the mean attitude score in the high school diploma holding caregivers was better than those of with lower education $(\mathrm{P}=0.018)$. Post hoc Scheffe test disclosed the difference between the 2nd and 4th weekly care hours as significant $(\mathrm{P}=0.033)$. The analysis showed the attitude in the caregivers with another patient with psychiatric disorder in their family plus the old ill member was lower than those of other caregivers and this difference was statistically significant $(P=0.036)$. Besides, the findings showed that other demographics (age, gender, marital status, economic condition, employment and kinship with the patient) had no significant statistical relationship with attitude toward long-term care.

\section{Discussion and Conclusion}

The obtained results demonstrated that $71 \%$ of the caregivers had negative attitude toward providing long-term care for the patients with psychiatric disorder. The current study findings were compatible with those of some other studies $(4,10,26)$; while not consistent with some other ones $(12,17)$. In a research aimed to outline the American and Japanese-American families' cultural differences and attitude toward caring for old people afflicted with Hawaiian chronic disease, the Japanese caregivers who lacked any sort of social support had more negative attitude compared with the white Americans (27). In the current research, attitude had significant association with three caregivers' demographics including educational level, the affliction of other family members to psychiatric disorders and the hours caring for the elderly. In other words, the attitude scores of a high school diploma holding caregiver was better than that of a higher education holder. These 
Table 1. The Demographic Data of Caregivers for the Elderly Patients with Psychiatric Disorders

\begin{tabular}{|c|c|c|c|}
\hline Demographic Data & & Frequency & Percent \\
\hline \multicolumn{4}{|l|}{ Gender } \\
\hline Male & & 104 & 52.00 \\
\hline Female & & 0.0096 & 48.00 \\
\hline \multicolumn{4}{|l|}{ Age } \\
\hline$>40$ & & 33 & 16.7 \\
\hline $40-59$ & & 113 & 57.4 \\
\hline \multicolumn{4}{|c|}{ Mean $\pm S D=51.24 \pm 12.96$} \\
\hline \multicolumn{4}{|l|}{ Education } \\
\hline Under high school diploma & & 0.0012 & 6.00 \\
\hline High school diploma & & 0.0090 & 45 \\
\hline College education & & 0.0098 & 49 \\
\hline \multicolumn{4}{|l|}{ Marital status } \\
\hline Single & & 0.0013 & 6.00 \\
\hline Married & & 0.0187 & 94 \\
\hline \multicolumn{4}{|l|}{ Economic status } \\
\hline Poor & & 0.00 .06 & 030.00 \\
\hline Average & & 0.00135 & 97.5 \\
\hline Well-off & & 0.0058 & 29.2 \\
\hline \multicolumn{4}{|l|}{ Employment } \\
\hline Housewife & & 0.0040 & 20.00 \\
\hline Farmer & & 0.0032 & 16.00 \\
\hline Self-employed & & 0.0033 & 16.5 \\
\hline Employee & & 0.0066 & 33.00 \\
\hline Retired & & 0.0029 & 14.5 \\
\hline \multicolumn{4}{|c|}{ Another patient with psychiatric disorder in family } \\
\hline No & & 0.00173 & 86.4 \\
\hline Yes & & 0.0027 & 13.6 \\
\hline \multicolumn{4}{|l|}{ Weekly care hours } \\
\hline$<24, \mathrm{~h}$ & & 0.0028 & 14.00 \\
\hline $24-34, \mathrm{~h}$ & & 0.0071 & 35.5 \\
\hline $35-44, \mathrm{~h}$ & & 0.0080 & 40.00 \\
\hline$>44, \mathrm{~h}$ & & 0.0021 & 10.5 \\
\hline \multicolumn{4}{|l|}{ Relation } \\
\hline Spouse & & 0.0059 & 29.5 \\
\hline Child & & 0.0097 & 48.5 \\
\hline Daughter/son-in-law & & 0.0022 & 11.00 \\
\hline Other relatives & & 0.0022 & 11.00 \\
\hline
\end{tabular}

findings did not match with the results of some studies such as the ones by Caqueo-Urizar and Shinde $(10,22)$.
Increased knowledge and information of the caregivers regarding psychiatric disorders and outcomes such 
Table 2. The Demographic Data of the Elderly with Psychiatric Disorders

\begin{tabular}{|c|c|c|}
\hline Demographic Data & Frequency & Percent \\
\hline \multicolumn{3}{|l|}{ Gender } \\
\hline Males & 102 & 51 \\
\hline Female & 98 & 49 \\
\hline \multicolumn{3}{|l|}{ Age, $y$} \\
\hline $60-69$ & 92 & 46 \\
\hline $70-79$ & 83 & 41.5 \\
\hline$<80$ & 25 & 12.5 \\
\hline \multicolumn{3}{|c|}{ Mean $\pm S D=71.96 \pm 7.27$} \\
\hline \multicolumn{3}{|l|}{ Education } \\
\hline Illiterate & 72 & 36 \\
\hline Under high school diploma & 61 & 30.5 \\
\hline High school diploma & 44 & 22 \\
\hline Higher educations & 32 & 11.5 \\
\hline \multicolumn{3}{|l|}{ Marital status } \\
\hline Single & 10 & 5 \\
\hline Married & 109 & 54.5 \\
\hline Widow & 81 & 40.5 \\
\hline \multicolumn{3}{|l|}{ Employment } \\
\hline Unemployed & 92 & 46.2 \\
\hline Farmer & 49 & 6 \\
\hline Self-employed & 5 & 2.6 \\
\hline Retired & 53 & 26.6 \\
\hline \multicolumn{3}{|l|}{ Disease duration, $y$} \\
\hline $10<$ & 35 & 17.6 \\
\hline $10-19$ & 85 & 7.42 \\
\hline $20-29$ & 52 & 26.1 \\
\hline$>30$ & 27 & 13.6 \\
\hline \multicolumn{3}{|c|}{ Mean $\pm S D=18.05 \pm 9.65$} \\
\hline \multicolumn{3}{|l|}{ Type of psychiatric disorder } \\
\hline Schizophrenia & 59 & 29.5 \\
\hline Anxiety & 14 & 7 \\
\hline Mania & 43 & 21.5 \\
\hline Depression & 63 & 31.5 \\
\hline More than one disorder & 21 & 10.5 \\
\hline
\end{tabular}

as: not being cured, long-term care, medical expenses and economic problems, care induced physical and psychological effects on the family members, losing social roles, time restriction for family setting presence and dealing with the elderly care created additional concerns leading to negative attitude in them. According to Table 1, the major- ity of the caregivers holding high school diploma were housewives and/or self-employed and as a result, had sufficient time to deal with personal, social and occupational errands and customized care plan. This point led the caregivers to perform their roles appropriately and ultimately, to come up with positive attitude. The attitude of the caregivers taking care of another patient with psychiatric disorder at home was negative. It appears that the presence of an elderly patient with psychiatric disorder induces pressure and tension in the family circumstances. Now if another patient with similar illness is added to this family, this tension can get doubled, resulting in more negative attitude in the caregivers. The attitude scores were significantly associated with the care hours. The more the care hours per week, the more negative the attitude. This finding was consistent with the results of some other studies such as those of Angela-Cole and Caqueo-Urízar (10, 28). This matter showed that long-term caring for a patient with psychiatric disorder at home can create tension and negative attitude in the caregivers (10). Though in the conducted research cases, females were introduced as the main caregivers, in the current study, more than half of the caregivers (52\%) were male. This finding matches the Indian research based results (22). Of course, in the current study main caregivers were the patient's children as $48.5 \%$ whose mean attitude scores were lower than that of other caregivers (spouse, daughter-in-law, daughter and son-inlaw). Yet, this difference was not significant. While in some studies $(10,12,26)$, the main caregivers were spouses and daughters, results were compatible with the present study findings. Of course, the existing difference somewhat depends on the study setting cultural context. The role of males in the family as a head and the supplier of family financial needs and having independence results in playing the main role in providing care. In the current research, no significant relationship was spotted between attitude and gender. The obtained result was not consistent with the results of another research where the mothers' care related attitude was reported positive compared with that of the fathers (12). Also in this study, age exposed no significant relationship with caregivers' attitude. But in another research, the caregivers' age was significantly related to attitude. Therefore, the older caregivers had more negative attitude toward care (10). In this research, the scores of attitude had no significant relationship with economic status, though the mean scores of attitude in economically poor caregivers was lower, in agreement with the findings of another study (10). In another research, the economically well-off caregivers had better attitude compared to the ones with bad economic status (12). In the existing survey, the patient care hours and also the number of patients with psychiatric disorders in the family were signifi- 
Table 3. The Caregivers' Attitude Numerical Indicators in Terms of Demographic Data

\begin{tabular}{|c|c|c|c|}
\hline Demographic Data & Mean & SD & Test Result \\
\hline Gender & & & ${ }^{*} \mathrm{t}=-0.636, \mathrm{df}=198, \mathrm{P}$ value $=0.526$ \\
\hline Male & 39.15 & 5.41 & \\
\hline Female & 39.63 & 5.25 & \\
\hline Age & & & ${ }^{*} \mathrm{~F}=1.057, \mathrm{P}$ value $=0.390$ \\
\hline$<30$ & 37.71 & 4095 & \\
\hline $30-39$ & 39.37 & 5.24 & \\
\hline $40-49$ & 39.39 & 5.31 & \\
\hline $50-59$ & 38.10 & 5.23 & \\
\hline $60-69$ & 41.60 & 5.21 & \\
\hline $70-79$ & 39.71 & 5.60 & \\
\hline Education & & & ${ }^{* *} \mathrm{~F}=3.46, \mathrm{P}$ value $=0.017$ \\
\hline Under high school diploma & 38.92 & 5.07 & \\
\hline High school diploma & 40.52 & 5.27 & \\
\hline Higher educations & 36.81 & 4.36 & \\
\hline Marital status & & & ${ }^{*} \mathrm{t}=1.601, \mathrm{df}=117, \mathrm{P}$ value $=0.112$ \\
\hline Single & 39.45 & 5.45 & \\
\hline Married & 42.2 & 6.23 & \\
\hline Economic status & & & ${ }^{* *} \mathrm{~F}=0.526, \mathrm{P}$ value $=0.592$ \\
\hline Poor & 39.33 & 5.35 & \\
\hline Average & 37.67 & 5.85 & \\
\hline Well-off & 39.69 & 5.16 & \\
\hline Employment & & & ${ }^{* *} \mathrm{~F}=1.045, \mathrm{P}$ value $=0.385$ \\
\hline Housewife & 39.14 & 5.62 & \\
\hline Farmer & 40.18 & 5.35 & \\
\hline Self-employed & 40.1 & 5.72 & \\
\hline Employee & 39.74 & 5.34 & \\
\hline Retired & 38.34 & 4.94 & \\
\hline Another patient with psychiatric disorder in family & & & ${ }^{*} \mathrm{t}=2.111, \mathrm{df}=197, \mathrm{P}$ value $=0.046$ \\
\hline No & 39.96 & 5.23 & \\
\hline Yes & 39.68 & 5.31 & \\
\hline Weekly patient care hours & & & ${ }^{* *} \mathrm{~F}=3, \mathrm{P}$ value $=0.032$ \\
\hline$<24, \mathrm{~h}$ & 37.37 & 5.12 & \\
\hline $24-34, \mathrm{~h}$ & 39.96 & 3.97 & \\
\hline $35-44, \mathrm{~h}$ & 40.36 & 4.91 & \\
\hline$>44, \mathrm{~h}$ & 39.32 & 5.82 & \\
\hline Relation & & & ${ }^{* *} \mathrm{~F}=2.241, \mathrm{P}$ value $=0.085$ \\
\hline Spouse & 36.38 & 5.19 & \\
\hline Child & 40.16 & 5.49 & \\
\hline Daughter/son-in-law & 38.5 & 4.96 & \\
\hline Other relatives & 40.44 & 4.42 & \\
\hline
\end{tabular}


cantly inversely associated with attitude. That is, the more the number of the patients with psychiatric disorders in the family, the more negative the caregivers' attitude was. Long-term care of the elderly patients with psychiatric disorder along with another patient at home imposes additional pressure and fatigue on the caregivers. This psychological burden can induce negative attitude in the caregivers. Of course, in the developed nations, respite care is applied to get rid of this nuisance (29). In this approach, family caregivers seek help from public, private or charity care centers to take care of the elderly and have some while off as oneself or family and especially the old person. This approach can lower the long-term mental care induced pressure, tension and exhaustion in the caregivers and change their attitude. Unfortunately, in Iran no center or institute is suitably developed to assist the families in this respect. By designing educational programs by national media about old age and the prevalent diseases at this period of life, the families' knowledge is promoted in such a manner that both the attitude and the perspective of the family caregivers toward the disease and the elderly change and also the stigma is reduced. Based on the findings, it is suggested to promote the mental health of the elderly patients with psychiatric disorder and their caregivers, it is needed to develop family-oriented educational, counseling and supportive programs and perform analytical and interventional studies. The study had some limitations, the lack of random sampling was due to the specific circumstances of patients and their caregivers that can restrain the potential to generalize the results. The sampling method was available, and only elderly patients with psychiatric disorders investigated in the study referred to the hospital; in fact the number of seniors who live at home or in nursing homes was not investigated in the current study.

\section{Acknowledgments}

This paper was part of a research project thesis titled "studying attitude toward the provision of long-term care with family burden caring the psychotic elderly at Zare hospital in Sari", approved by Iran University of Medical Sciences in 2015 under the code: 9211580201; the study was financially supported by midwifery and nursing college, Iran University of Medical Sciences and the cooperation of Mazandaran University of Medical Sciences, psychiatric research department and behavioral sciences of Medical Sciences University. Besides, the authors appreciate the cooperation and assistance of Zare hospital officials and personnel and all of the patients' caregivers.

\section{Footnotes}

Authors' Contribution: Data gathering and drafting the manuscript, Azar Ramezani; study concepts, supervision and design of the study Farideh Bastani; supervision, administration and translation of the manuscript, Hamideh Azimi; statistical analyses and interpretation of data, Hamid Haghani.

Declaration of Interest: There was no conflict of interest regarding the material used in the current study.

Funding/Support: The research was financially supported by midwifery and nursing college, Iran University of Medical Sciences, Tehran, Iran.

\section{References}

1. Khodadadi N, Baghaei M, Mahmoodi H, Sheikholeslami F. Quality of life schizophrenic patient [in Persian]. Zahedan J Res Med Sci. 2011;53(1):61.

2. Carra G, Cazzullo C, Clerici M. The association between expressed emotion, illness severity and subjective burden of care in relatives of patients with schizophrenia. Findings from an Italian population. BMC Psychiatry. 2012;12(1) doi: 10.1186/1471-244x-12-140.

3. Mohammadi F, Babaee M. Effect of Participating Supporting Groups on Spiritual Health and Care Burden in Family Member Caregivers of Alzheimer's suffering elderly [in Persian ].Iran Elderly J. 2010;6(19):2937.

4. Lauber C, Rössler W. Relatives and their attitude to early detection of schizophrenic psychosis. BJp Psych. 2003;27(1):134-6. doi: 10.1192/pb.02-158.

5. Gutiérrez-Maldonado J, Caqueo-Urízar A, Ferrer-García M. Effects of a psychoeducational intervention program on the attitudes and health perceptions of relatives of patients with schizophrenia. Social Psychi Epidemiol. 2008;44(5):343-8. doi: 10.1007/s00127-008-0451-9.

6. Azaerbayjani M, Salarifar M, Abbasi A, Kaviani M, Mousavi ASL SM. Social Psychology with Attitude Toward Islamic References. Tehran: SAMT Publication; 2010.

7. Vogelt T, Bohner G, Wank M. Attitudes and attitude change. Social Psychology: A Modular Course. New York: Routledge; 2014.

8. Birami M. Family and its pathology. Tabriz: Idin; 2008.

9. Ng SL, Martin JL, Romans SE. A community's attitudes towards the mentally ill. N Engl J Med. 2008;108(1013):505-8.

10. Caqueo-Urízar A, Gutiérrez-Maldonado J, Ferrer-García M, PeñalozaSalazar C, Richards-Araya D, Cuadra-Peralta A. Attitudes and burden in relatives of patients with schizophrenia in a middle income country. BMC Family Practice. 2011;12(1).

11. Awad AG, Voruganti LN. The burden of schizophrenia on caregivers: a review. Pharmaco Eco. 2008;26(2):149-62. [PubMed:18198934].

12. Boeni M, Ramezani T, Khodadadi N, MousaviLotfi M, HaghDoust A, Yegane M. Schizophrenic Caregiver's Attitude toward Know-how behind Caring at home [in Persian]. Holistic Nursing Midwifery J. 2012;1(1):54-62.

13. Scott CB. Alzheimer's disease Caregiver Burden: Does Resilience Matter? PhD diss. Tennessee: University of Tennessee; 2010.

14. Kuipers L. Family burden in schizophrenia: Implication for services. Social Psychiatry Epidemiology. 2007;28(1):207-10.

15. WHO . Ageing and life-course Geneva: Worl health organization; 2013. Available from: http://www.who.int/ageing/en/.

16. Miezaee M, Shams M. Analyzing Iran Demographic challenges and Issues and its Outcomes. ; 2010. 
17. Hindle A, Coates A, Kingston P. Nursing care of older people. New York: Oxford University Press; 2010.

18. Sadock BJ, Sadock VA. Kaplan and Sodock's synopsis of psychiatry: Behavioral sciences, clinical psychiatry. Philadelphia: Lippincott Williams and Wilkins; 2014.

19. Alexopoulus G. Pharmacotherapy of depressive disorders in older patients. Minneapolis: McGraw-Hill Health; 2007.

20. Sepeher Manesh Z, Ahmandvand A, Ghoreyshi F, Asarian F, Mousavi G, Saee R, et al. Investigating psychological disorders in Kashan Public in 2008 [in Persian]. Iran J Epidemiol. 2010;1(2):16-24.

21. Medical Education Health Department . Adultpsychiatric diseases Care Instructions (exclusively for physicians). Tehran: Medical Education Health Department; 2007.

22. Shinde M, Desai A, Pawar SH. Attitudes and Practices among Caregivers of Patients with Schizophrenia in Western Maharashtra. IJSR 2014;3(5):516-22.

23. O'Hara RE, Hull JG, Lyons KD, Bakitas M, Hegel MT, Li Z, et al. Impact on caregiver burden of a patient-focused palliative care interven- tion for patients with advanced cancer. Palliative and Supportive Care. 2010;8(04):395-404. doi:10.1017/s1478951510000258.

24. Klein WC. Measuring caregiver attitude toward the provision of long term care. J Social Service Res. 1992;16(3-4):147-62.

25. Corcoran JFK. titel Measures for clinical practice: a sourcebook. 3 ed. New York: The Free Press Year; 2000.

26. Grover S, Dutt A. Perceived burden and quality of life of caregivers in obsessive-compulsive disorder. Psychiatry Clin Neurosci. 2011;65(5):416-22. doi: 10.1111/j.1440-1819.

27. McLaughlin L. Factors That Contribute to Stress among Japanese American and Caucasian - American Family Caregiver of Frail elders, Unpublished PhD thesis. Hawaii: University of Hawaii; 2002.

28. Anngela-Cole L, Hilton JM. The Role of Attitudes and Culture in Family Caregiving for Older Adults. Health Care Services Quart. 2009;28(23):59-83.

29. Hocking B. Reducing mental illness stigma and discrimination - everybody's business. Med J Aust. 2003;178(5):47-8. 